\title{
KARAKTERISTIK PERDARAHAN ANTEPARTUM DAN PERDARAHAN POSTPARTUM
}

\author{
${ }^{1}$ Londok THM \\ ${ }^{2}$ Lengkong RA \\ ${ }^{2}$ Suparman E
}

\author{
${ }^{1}$ Kandidat Skripsi Fakultas Kedokteran Universitas Sam Ratulangi Manado \\ ${ }^{2}$ Bagian Obstetri dan Ginekologi Fakultas Kedokteran Universitas Sam Ratulangi Manado
}

\begin{abstract}
The most important cause of hemorrhage in pregnancy and parturition are antepartum hemorrhage and postpartum hemorrhage. The purpose of this research is to investigate the characteristics of antepartum hemorrhage and postpartum hemorrhage at Prof DR. R.D Kandou General Hospital Manado in 2011. This research used a retrospective descriptive through medical records at BLU RSUP Prof dr R.D Kandou Manado in January 2011 to December 2011. From 4155 parturition case in 2011, there were 60 cases (1,44\%) of antepartum hemorrhage and 36 case $(0,86 \%)$ of postpartum hemorrhage. The highest sociodemographic distribution found : in mother's age between 35-39 years old, in highschool students, and housewives . The highest medico obstetric distribution found: 17 cases $(28,3 \%)$ of first parity and 17 cases $(28,3 \%)$ second parity of antepartum hemorrhage and 18 cases $(50 \%)$ of first parity in postpartum hemorrhage, in gestational age between $37-42$ week, 32 cases $(53,3 \%)$ of antepartum hemorrhage and 30 cases $(83,3 \%)$ of postpartum hemorrhage. The perabdominal parturition (caesarean section), there were 55 cases (91,7\%) of antepartum hemorrhage and 22 case $(61,1 \%)$ of pervaginam in postpartum hemorrhage. The causes of antepartum hemorrhage were placenta previa in 59 cases $(98,3 \%)$ and retained placenta in 10 cases $(27,8 \%)$. The most number of antenatal care check ups were $\geq 4 \mathrm{x}$ check ups on antepartum hemorrhage cases and $<4 \mathrm{x}$ on postpartum hemorrhage cases. These high incidents needs to be noted by all parties. Pregnant women who are in risk for antepartum hemorrhage and postpartum hemorrhage need to be routinety and checked up and carefulle for their pregnancy.
\end{abstract}

Keywords: Antepartum Hemorrhage, Postpartum Hemorrhage, Patient Characteristic.

Abstrak: Penyebab perdarahan pada kehamilan dan persalinan yang penting adalah perdarahan antepartum dan perdarahan postpartum. Tujuan penelitian ini untuk mengetahui karakteristik perdarahan antepartum dan perdarahan postpartum di BLU RSUP Prof DR. R.D Kandou Manado tahun 2011. Penelitian ini menggunakan metode retrospektif deskriptif melalui rekam medik di BLU RSUP Prof dr R.D Kandou Manado tahun 2011. Dari 4155 total persalinan seluruhnya pada tahun 2011, terdapat 60 kasus (1,44\%) perdarahan antepartum dan 36 kasus $(0,86 \%)$ perdarahan postpartum. Distribusi sosiodemografi tertinggi : umur ibu 35-39 tahun, pendidikan terakhir tamat SMA, pekerjaan ibu rumah tangga. Distribusi mediko obstetri tertinggi: 17 kasus (28,3\%) paritas pertama dan 17 kasus (28,3\%) paritas kedua pada perdarahan antepartum dan 18 kasus (50\%) paritas pertama pada perdarahan postpartum, usia kehamilan biasanya 37-42 minggu yaitu 32 kasus (53,3\%) perdarahan antepartum dan 30 kasus (83,3\%) perdarahan postpartum. Tindakan persalinan perabdominal (seksio sesarea) 55 kasus (91,7\%) perdarahan antepartum dan 22 kasus (61,1\%) pervaginam perdarahan post partum. Penyebab perdarahan antepartum terbanyak adalah plasenta previa dan perdarahan postpartum disebabkan oleh sisa plasenta. Kebanyakan jumlah pemeriksaan antenatal care $₫ 4 x$ pemeriksaan pada perdarahan antepartum dan $<4 \mathrm{x}$ pemriksaan pada perdarahan postpartum. Tingginya angka kejadian ini perlu mendapat perhatian dari semua pihak. Ibu-ibu hamil yang memiliki faktor 
resiko untuk terjadinya perdarahan antepartum dan perdarahan post partum agar selalu waspada dan selalu memeriksakan kehamilannya kepada tenaga ahli secara berkala dan teratur.

Kata kunci: Perdarahan Antepartum, Perdarahan Postpartum, Karakteristik Penderita.

Angka Kematian Ibu merupakan tolak ukur untuk menilai baik buruknya pelayanan kebidanan dan sebagai indikator tingkat kesejahteraan ibu. Angka Kematian Ibu (Maternal Mortality Ratio, MMR) didasarkan pada risiko kematian ibu berkaitan dengan proses melahirkan, persalinan, perawatan obstetrik, komplikasi kehamilan dan masa nifas. Penyebab perdarahan pada kehamilan yang penting adalah perdarahan antepartum dan perdarahan postpartum. ${ }^{1,2,3}$

Perdarahan yang terjadi pada umur kehamilan yang lebih tua setelah melewati trimester III disebut dengan perdarahan antepartum. ${ }^{4} \quad$ Perdarahan antepartum merupa-kan suatu kasus gawat darurat yang berkisar 3-5\% dari seluruh persalinan. Penyebab utama perdarahan antepartum yaitu plasenta previa dan solusio plasenta; penyebab lainnya biasanya pada lesi lokal vagina/ serviks. ${ }^{6}$ Plasenta previa merupakan penyulit kehamilan hampir 1 dari 200 persalinan atau 1,7 \% sedangkan untuk solusio plasenta 1 dalam 155 sampai 1 dari 225 persalinan atau $<0,5 \%$. Lebih dari setengah dari seluruh kematian ibu terjadi dalam waktu 24 jam setelah melahirkan paling sering dari perdarahan yang berlebihan. $^{7}$

Pendarahan postpartum dikaitkan dengan 19,1 \% dari seluruh kematian di rumah sakit setelah melahirkan. ${ }^{8}$ Diseluruh dunia diperkirakan 140.000 perempuan meninggal karena perdarahan postpartum setiap tahunsatu setiap 4 menit. Peningkatan kejadian perdarahan postpartum dari $1,5 \%$ pada tahun 1999 menjadi 4,1\% pada tahun 2009 dan pada perdarahan postpartum yang disebabkan oleh atonia uteri meningkat dari 1\% pada tahun 1999 menjadi 3,4\% pada tahun 2009. Perdarahan postpartum didefinisikan sebagai kehilangan darah lebih dari $500 \mathrm{~mL}$ setelah persalinan vaginam atau lebih dari $1.000 \mathrm{~mL}$ setelah persalinan abdominal. Perdarahan dalam jumlah ini dalam waktu kurang dari 24 jam disebut sebagai perdarahan postpartum primer, dan apabila perdarahan ini terjadi lebih dari 24 jam disebut sebagai perdarahan post partum sekunder. ${ }^{7,9}$

Apabila terjadi perdarahan yang berlebihan pasca persalinan harus dicari etiologi yang spesifik. Atonia uteri, retensio plasenta, sisa plasenta, dan laserasi traktus genitalia bawah merupakan penyebab sebagian besar perdarahan postpartum. Meskipun demikian, dua pertiga kasus perdarahan postpartum terjadi pada ibu dengan faktor resiko yang tidak dapat diidentifikasi. $^{10}$

Banyak faktor risiko telah dikaitkan dengan perdarahan antepartum dan perdarahan postpartum, namun sangatlah penting untuk identifikasi awal faktor risiko karena perdarahan antepartum dan perdarahan perdarahan postpartum tetap menjadi kontributor yang signifikan untuk morbiditas dan mortalitas ibu di seluruh dunia. $^{11,12}$

Di seluruh rumah sakit di Indonesia tahun 2005 terdapat 2.346 kasus perdarahan antepartum atau sebesar 1,37 \% sedangkan kasus perdarahan postpartum sebanyak 8.212 dengan presentasi $4,81 \%{ }^{13}$

Berdasarkan hal tersebut, dalam rangka menyelesaikan tugas karya tulis ilmiah sarjana kedokteran, maka penulis ingin meneliti karakteristik perdarahan antepartum dan perdarahan postpartum di BLU RSUP Prof DR. R.D Kandou Manado tahun 2011.

\section{METODE}

Desain penelitian ini adalah penelitian deskriptif retrospektif melalui pengumpulan data. Subjek Penelitian diambil dari kasus perdarahan antepartum (HAP) dan perdarahan post partum (HPP) di BLU RSUP Prof DR. R.D Kandou Manado selama periode Januari 2011 sampai Desember 2011 yang diperoleh dari catatan rekam medik dan buku register obstetri di bagian 
Obstetri dan Ginekologi. Variabel yang akan diteliti adalah distribusi kasus perdarahan ante-partum dan perdarahan post partum berdasarkan:

1. Sosiodemografi meliputi: umur, agama, tingkat pendidikan, dan pekerjaan.

2. Mediko obstetri meliputi : paritas, umur kehamilan, tindakan persalinan.

3. Penyebab perdarahan perdarahan antepartum dan penyebab perdarahan post partum

4. Jumlah pemeriksaan antenatal care $<4 \mathrm{x}$ dan $\geq 4 \mathrm{x}$.

\section{HASIL}

Telah diteliti selama 1 tahun secara retrospektif yang dilakukan di ruang bersalin RSUP Prof DR R.D Kandou periode 1 januari 2011-31 Desember 2011 yaitu terdapat 4153 kasus persalinan dengan 70 kasus perdarahan antepartum tetapi yang diteliti hanya 60 kasus (1,44\%), 3 kasus tidak diambil sebagai sampel penelitian karena tidak memilki catatan rekam medik yang lengkap dan 7 kasus hanya melakukan pemeriksaan dan tidak melakukan tindakan persalinan sedangkan 36 kasus (0,86 \%) terdapat perdarahan post partum.

Tabel 1. Distribusi perdarahan antepartum dan perdarahan post partum di Ruang Bersalin

\begin{tabular}{cccccc}
\hline Thn & $\begin{array}{l}\text { Jumlah } \\
\text { Persalinan }\end{array}$ & $\begin{array}{l}\text { Perdarahan } \\
\text { Antepartum } \\
\text { (HAP) }\end{array}$ & $\begin{array}{c}\text { Perdarahan } \\
\text { Postpartum } \\
\text { (HPP) }\end{array}$ \\
\hline \multirow{2}{*}{2011} & 4155 & Jumlah & $\%$ & Jumlah & $\%$ \\
& & 60 & 1,44 & 36 & 0,86 \\
\hline
\end{tabular}

Tabel 2. Distribusi HAP dan HPP berdasarkan sosiodemografi

\begin{tabular}{|c|c|c|c|c|c|}
\hline & \multirow[t]{2}{*}{$\begin{array}{c}\text { Karakteristik } \\
\text { Ibu }\end{array}$} & \multicolumn{2}{|c|}{$\begin{array}{l}\text { Perdarahan } \\
\text { Antepartum } \\
\text { (HAP) }\end{array}$} & \multicolumn{2}{|c|}{$\begin{array}{c}\text { Perdarahan } \\
\text { Postpartum } \\
\text { (HPP) }\end{array}$} \\
\hline & & Jumlah & $\%$ & Jumlah & $\%$ \\
\hline \multirow{7}{*}{ Umur } & $<20$ thn & 1 & 1,7 & 6 & 16,8 \\
\hline & $20-24$ thn & 6 & 10 & 3 & 8,3 \\
\hline & $25-29$ thn & 12 & 20 & 8 & 22.2 \\
\hline & $30-34$ thn & 14 & 23,3 & 7 & 19,4 \\
\hline & $35-39$ thn & 15 & 25 & 9 & 25 \\
\hline & $>40$ thn & 12 & 20 & 3 & 8,3 \\
\hline & Total & 60 & 100 & 36 & 100 \\
\hline \multirow{6}{*}{$\begin{array}{l}\text { Pendidikan } \\
\text { Terakhir }\end{array}$} & SD & 11 & 18,3 & 1 & 2,78 \\
\hline & SMP & 15 & 25 & 9 & 25 \\
\hline & SMA & 26 & 43,33 & 23 & 63,89 \\
\hline & DIII & 4 & 6,67 & - & - \\
\hline & S1 & 4 & 6,67 & 3 & 8,33 \\
\hline & Total & 60 & 100 & 36 & 100 \\
\hline \multirow{5}{*}{ Pekerjaan } & IRT & 48 & 80 & \multicolumn{2}{|c|}{83,3} \\
\hline & Swasta & 6 & 10 & \multicolumn{2}{|c|}{8,3} \\
\hline & Pendeta & 1 & 3,3 & \multicolumn{2}{|c|}{2,8} \\
\hline & PNS & 4 & 6,7 & \multicolumn{2}{|c|}{5,6} \\
\hline & Total & 60 & 100 & \multicolumn{2}{|c|}{100} \\
\hline
\end{tabular}


Tabel 3. Distribusi penderita HAP dan HPP berdasarkan mediko obstetri

\begin{tabular}{|c|c|c|c|c|c|c|}
\hline \multicolumn{2}{|c|}{ Karakteristik Ibu } & \multicolumn{2}{|c|}{$\begin{array}{c}\text { Perdarahan } \\
\text { Antepartum } \\
\text { (HAP) }\end{array}$} & \multicolumn{3}{|c|}{$\begin{array}{l}\text { Perdarahan } \\
\text { Postpartum } \\
\text { (HPP) }\end{array}$} \\
\hline & & Jum & ah \% & Juml & & $\%$ \\
\hline \multirow[t]{7}{*}{ Paritas } & P0 & 10 & 16,7 & - & & - \\
\hline & P1 & 17 & 28,3 & 18 & 50 & \\
\hline & P2 & 17 & 28,3 & 8 & 22 & \\
\hline & P3 & 6 & 10 & 7 & 19 & \\
\hline & $>\mathrm{P} 4$ & 10 & 16,7 & 3 & 8,3 & \\
\hline & Total & 60 & 100 & 36 & 10 & \\
\hline & $<37$ & 27 & 45 & 4 & 11 & \\
\hline Umur & $37-42$ & 32 & 53,3 & 30 & 83 & \\
\hline \multirow[t]{2}{*}{ Kehamilan } & $>42$ & 1 & 1,7 & 2 & 5 & \\
\hline & Total & 60 & 100 & 36 & 10 & \\
\hline Tindakan & Pervaginam & 5 & 8,3 & 22 & 61 & \\
\hline \multirow[t]{2}{*}{ Persalinan } & Perabdominal & 55 & 91,7 & 14 & 38 , & \\
\hline & Total & 60 & 100 & 36 & 10 & \\
\hline
\end{tabular}

Tabel 4. Distribusi penderita perdarahan antepartum berdasarkan penyebab perdarahan antepartum

\begin{tabular}{lrc}
\hline $\begin{array}{l}\text { Perdarahan } \\
\text { Antepartum } \\
\text { (HAP) }\end{array}$ & Jumlah & $\%$ \\
\hline Plasenta Previa & 59 & 98,3 \\
Solusio Plasenta & 1 & 1,7 \\
Total & 60 & 100 \\
\hline
\end{tabular}

Pada tabel 4, terlihat bahwa distribusi perdarahan antepartum berdasarkan penyebab perdarahan antepartum yang paling banyak yaitu plasenta previa sebesar 59 dari 60 kasus dengan nilai presentasi sebesar $98,3 \%$.

Tabel 5. Distribusi Penderita perdarahan postpartum berdasarkan penyebab perdarahan postpartum.

\begin{tabular}{lcc}
\hline \multicolumn{1}{c}{$\begin{array}{c}\text { Perdarahan } \\
\text { Postpartum } \\
\text { (HPP) }\end{array}$} & Jumlah & $\mathbf{\%}$ \\
\hline Atonia Uteri & 8 & 22,2 \\
Robekan Jalan lahir & 5 & 13,9 \\
Sisa Plasenta & 10 & 27,8 \\
Retensio plasenta & 9 & 25 \\
Ruptur Uteri & 4 & 11,1 \\
Total & 36 & 100 \\
\hline
\end{tabular}

Pada tabel 5, penyebab perdarahan pospartum yang paling banyak yaitu sisa plasenta 10 dari 36 kasus dengan nilai presentasi sebesar 27,8\%.

Tabel 6. Distribusi Penderita perdarahan antepartum dan perdarahan berdasarkan jumlah pemeriksaan antenatal care

\begin{tabular}{lcrcc}
\hline Jumlah PAN & $\begin{array}{c}\text { Perdarahan } \\
\text { Antepartum } \\
\text { (HAP) }\end{array}$ & \multicolumn{2}{c}{$\begin{array}{c}\text { Perdarahan } \\
\text { Postpartum } \\
\text { (HPP) }\end{array}$} \\
\hline & Jumlah & Jumlah & $\%$ \\
$<4 \mathrm{x}$ & 27 & 45 & 21 & 58,3 \\
$\geq 4 \mathrm{x}$ & 33 & 55 & 15 & 41,7 \\
Total & 60 & 100 & 36 & 100 \\
\hline
\end{tabular}

Pada tabel 6, terlihat bahwa jumlah pemeriksaan antenal care $\geq \mathbf{4}$ dng pemeriksaan lebih banyak ditemukan pada kasus perdarahan antepartum dan $<4 \mathrm{x}$ pemeriksaan pada perdarahan postpartum.

\section{BAHASAN}

Dalam penelitian yang dilakukan di RSUP Prof. Dr. R.D. Kandou selama periode 1 januari 2011 sampai 31 Desember 2011, ditemukan 60 kasus (1,44\%) 
perdarahan antepartum dan 36 kasus perdarahan post partum $(0,86 \%)$ dari total 4155 persalinan seluruhnya.

Pada Tabel 2. Karakteristik ibu yang mengalami perdarahan antepartum dan perdarahan post partum berdasarkan sosiodemografi: umur, pendidikan, pekerjaan, agama. Hasil penelitian menunjukkan bahwa presentasi pasien menurut umur adalah lebih banyak pada usia 35-39 tahun pada perdarahan antepartum dan perdarahan post partum yaitu perdarahan antepartum dengan jumlah 15 kasus atau 25\% sedangkan perdarahan post partum dengan jumlah 9 kasus sebesar 25\%. Hal ini berbeda dengan hasil penelitian yang dilakukan di rumah sakit Santa Elisabet Medan dan Rumah sakit Pringadi Medan selama 5 tahun dari tahun 2004-2008, yaitu kelompok usia yang paling banyak terdapat kasus perdarahan antepartum dan perdarahan post partum adalah kelompok usia 20-35 tahun. ${ }^{14,15}$

Dari hasil penelitian berdasarkan pendidikan terakhir dari ibu sebagian besar dengan pendidikan terakhir tamat SMA yaitu perdarahan antepartum dengan jumlah 26 kasus sebesar 43,3 \% dan 23 kasus atau $63,89 \%$ pada perdarahan post partum. Penelitian sebelumnya di rumah sakit pringadi medan tahun 2001-2004 mendapatkan hasil yaitu 40,5\% kasus perdarahan antepartum berpendidikan tingkat SMA dan penelitian pada tahun 2004-2008 di rumah sakit yang sama mendapatkan pendidikan terakhir SMA paling banyak juga ditemukan pada kasus perdarahan post partum yaitu 71 kasus atau 52,6\%. Pendidikan secara tidak langsung berpengaruh dalam menentukan dan mengambil sebuah keputusan. Tingginya tingkat pendidikan seorang wanita diharapkan semakin meningkat juga pengetahuan dalam mengantisipasi kesulitan kehamilan dan persalinan sehingga termotivasi untuk melakukan pengawasan kehamilan secara teratur. ${ }^{14,15}$

Dari hasil penelitian berdasarkan pekerjaan ibu didapatkan distribusi tertinggi dengan nilai presentasi $80 \%$ pada kasus perdarahan antepartum dan $83,3 \%$ pada kasus perdarahan post partum dengan mayoritas pekerjaannya adalah ibu rumah tangga.

Pada Tabel 3. Karakteristik ibu yang mengalami perdarahan antepartum dan perdarahan post partum berdasarkan mediko obstetri: paritas, umur kehamilan, dan tindakan persalinan. Hasil penelitian menunjukkan bahwa paritas pertama dan paritas kedua pada perdarahan antepartum memiliki jumlah kasus yang sama yaitu 17 kasus dengan nilai presentasi 28,3 \% dan lebih banyak paritas pertama terjadi perdarahan post partum. Menurut penelitian yang dilakukan Di RSUD Balembang Bari dimana pada multigravida mempunyai faktor resiko terjadi perdarahan antepartum yang disebabkan oleh plasenta previa yaitu 1,3 kali dibandingkan dengan primipara. ${ }^{16}$ Berbeda dengan kasus perdarahan postpartum Menurut penelitian Badriyah dkk tidak ada pengaruh paritas terhadap terjadinya perdarahan postpartum, penelitian yang sama juga oleh Selo Ojemo dan Okonofua yang menyatakan hal yang sama. Risiko pada paritas dapat ditangani dengan asuhan obstetrik yang lebih baik, sedangkan risiko pada paritas tinggi dapat dikurangi atau dicegah dengan keluarga berencana. ${ }^{17,18}$

Dari hasil penelitian berdasarkan umur kehamilan paling banyak ditemukan terjadi pada umur kehamilan 37-42 minggu atau pada kehamilan aterm. Dimana pada perdarahan antepartum dengan jumlah 32 kasus sebesar 53,3\% dan 30 kasus pada perdarahan post partum atau $83,3 \%$.

Dari hasil penelitian berdasarkan jenis persalinan didapatkan bahwa persalinan secara perabdominal (seksio sesarea) paling banyak dilakukan saat terjadi perdarahan antepartum dengan jumlah 55 kasus atau 91,7\% sedangkan tindakan persalinan secara pervaginam lebih banyak dilakukan pada perdarahan post dengan jumlah kasus 22 sebesar 61,1\%. Salah satu indikasi operasi seksio sesarea adalah plasenta previa dan solusio plasenta. Penanganan dengan persalinan pervaginam dilakukan pada pasien dengan diagnosis plasenta previa non totalis (plasenta previa lateralis, marginalis dan plasenta letak rendah) 
Menurut kepustakaan bahwa sebagian besar tindakan persalinan pada perdarahan antepartum yang disebabkan oleh plasenta previa dan solusio plasenta dilakukan secara peradominal (seksio sesarea). Hal yang sama Di RS Pringadi Medan yaitu pada perdarahan postpartum lebih banyak dilakukan persalinan pervaginam. ${ }^{14}$

Pada Tabel 4. Presentasi tertinggi perdarahan antepartum berdasarkan penyebab perdarahan antepartum adalah disebabkan oleh plasenta previa dimana didapatkan 59 kasus dengan jumlah presentasi 98,3 \% sedangkan yang disebabkan oleh solusio plasenta didapatkan hanya 1 kasus atau 1,7\%. Hasil yang sama yang ditemukan di rumah sakit Santa Elisabet Medan bahwa disrtibusi penyebab perdarahan yang paling tinggi disebabkan oleh plasenta previa sebesar 92,9\% sedangkan solusio plasenta sebesar 5,9\% , dan 1,2\% penyebab yang lain. Insiden di berbagai rumah sakit di Indonesia, pada plasena previa 0,28-2\% sedangkan untuk solusio plasenta 0,4-1,2\%. Dari seluruh kasus perdarahan antepartum, plasenta previa merupakan penyebab terbanyak. Oleh sebab itu pada kejadian perdarahan antepartum, kemungkinan plasenta previa harus dipikirkan terlebih dahulu. Menurunnya insidensi solusio plasenta mungkin disebabkan oleh kesadaran para ibu hamil terhadap faktor resiko solusio plasenta dan dengan semakin baiknya perawatan antenatal yang diberikan. ${ }^{15}$

Tabel 5. Dari hasil penelitian menunjukkan bahwa distribusi perdarahan post partum berdasarkan penyebab perdarahan post partum lebih banyak disebabkan oleh sisa plasenta dengan jumlah 10 kasus sebesar 27,8 \%, perbedaan yang sangat tipis secara berturut-turut disebabkan oleh retensio plasenta dengan 9 kasus (25\%), atonia uteri dengan 8 kasus (22\%), robekan jalan lahir dengan 5 kasus $(13,9 \%)$ dan ruptur uteri dengan 4 kasus $(11,1 \%)$. Hal ini berbeda dengan penelitian di RSUD Pringadi Medan selama kurun waktu 5 tahun yaitu distribusi penyebab perdarahan post partum lebih banyak disebabkan oleh retensio plasenta dengan jumlah 72 kasus sebesar $60.5 \% .^{14}$

Tabel 6. Berdasarkan jumlah pemeriksaan antenatal care ditemukan perbedaan jumlah pemeriksaan antenatal care. Lebih banyak terjadi perdarahan antepartum pada jumlah pemeriksaan antenatal $\geq 4 \mathrm{x}$ sedangkan $<4 \mathrm{x}$ pemeriksaan antenatal care lebih banyak terjadi perdarahan postpartum. Dimana jumlah pemeriksaan antenatal carkx pada perdarahan antepartum dengan jumlah 33 kasus dengan nilai presentasi 55\% dan $<4 \mathrm{x}$ pemeriksaan terjadi perdarahan post partum dengan jumlah 21 kasus sebesar 58,3\%. Pemeriksaan antenatal care dimulai sesegara setelah kehamilan diketahui. The American of Obstetrics and Gynecology (ACOG) merekomendasikan paling sedikt $11 \mathrm{x}$ kunjungan sedangkan WHO merekomendasikan 4x kunjungan. 18 Indonesia mengikuti rekomendasi WHO yaitu jumlah kunjungan antenatal care paling paling sedikt 4x. Hasil penelitian yang dilakukan oleh Brown et al di Kenya , didapatkan bahwa wanita dengan kunjungan antenatal $2 \mathrm{x}$ lebih memiliki hasil kehamilan dan persalinan yang lebih baik daripada wanita dengan kunjungan antenatal care sebanyak $3 x .{ }^{19}$ Jumlah pemeriksaan antenatal yang $<4 \mathrm{x}$ ataupщ $4 \mathrm{x}$ pemeriksaan tidak menjamin pada kehamilan dan persalinan yang baik nantinya. Penelitian yang dilakukan ribeiro et al di Brazil didapatkan bahwa 33,9\% wanita tidak mendapatkan pelayanan yang adekuat walaupun jumlah rata-rata kunjungan $\geq 6 x^{20}{ }^{20}$

Dapat dilihat bahwa bukan diukur dari berapa banyaknya jumlah kunjungan antenatal, namun perbedaan kualitas pelayanan antenatal yang diberikan dapat menjamin dan mengurangi komplikasi kehamilan seperti terjadinya perdarahan. Hal ini disebabkan karena adanya antenatal care maka tanda-tanda dini perdarahan yang berlebihan dapat didekteksi dan ditanggulangi dengan cepat sehingga perencanaan persalinan dapat dilakukan dengan maksimal. 


\section{UCAPAN TERIMA KASIH}

Penulis mengucapkan terima kasih kepada penguji 2 dan 3 serta kepada semua pihak yang secara langsung ataupun tidak langsung telah menumbuhkan gagasan dalam artikel ini.

\section{DAFTAR PUSTAKA}

1. Prawirohardjo S, Wiknjosastro. Kebidanan dalam masa lampau, kini, dan kelak. Dalam : Saifudin AB, Rachimhadi T, Wiknjosastro H. Ilmu kebidanan. Edisi Keempat. Jakarta: P.T. Bina Pustaka Sarwono Prawiraharjo; 2009 : p. 7-15.

2. Sharma G. Maternal, Perinatal and Neonatal Mortality in South-East Asia Region. Asian Journal of Epidemiology 5; 2012: p. 1-14.

3. Rahman SS, Myers JE, Gillham JC, Fitzmaurice R, Johnston TA. Postpartum hemorrhage secondary to uterine atony, complicated by platelet storage pool disease and partial placenta diffusa: a case report; 2008: 393.

4. Hadijanto B. Perdarahan Pada Kehamilan Muda. Dalam Saifudin AB. Rachimhadi T, Wiknjosastro H. Ilmu Kebidanan. Edisi Keempat. Jakarta: P.T. Bina Pustaka Sarwono Prawiraharjo; 2009: p. 459.

5. Manuaba IBG, Manuaba IAC, Manuaba IBGF. Pengantar Kuliah Obstetri. Jakarta: Buku Kedokteran EGC; 2007: p. 483-96.

6. Yoseph. Perdarahan selama kehamilan. Dalam: Cermin Dunia Kedokteran 1996.

7. Smith JR, Brennan BG. Postpartum Hemorrhage. Maternal-Fetal Medicine. Departments of Obstetrics \& Gynecology and Diagnostic Imaging. Credit Valley Hospital, Mississauga, Ontario ; 2012.

8. Bateman BT, Berman MF, Riley LE, Leffert LR. The epidemiology of postpartum hemorrhage in a large, nationwide sample of deliveries. Anesthesia \& Analgesia; 2010: $110: 1368-1373$.

9. Mochtar R, Lutan, editor. Sinopsis Obstetti. Obstetri Fisiologi Obstetri Patologi. Edisi ke-2. Jakarta: EGC; 1998: p 298-306.

10. Shane B. 2002. Mencegah Perdarahan Pasca Persalinan: Menangani Persalinan kala III. Out Look: Vol 19. h.1-8.

11. Rahman SS, Myers JE, Gillham JC, Fitzmaurice R, Johnston TA. Postpartum hemorrhage secondary to uterine atony, complicated by platelet storage pool disease and partial placenta diffusa: a case report; 2008: 393

12. Rajan,, Priya V. Postpartum Hemorrhage: Evidence-based Medical Interventions for Prevention and Treatment. Clinical Obstetrics \& Gynecology: 2010,Volume 53, Issue 1: p.165-181.

13. Profil Kesehatan Indonesia 2005. Departemen Kesehatan Republik Indonesia. Jakarta; 2007

14. Rahmi. "Karakteristik Penderita Perdarahan Post Partum Yang Datang Ke Rumah Sakit Pirngadi Medan tahun 20042008''[Skripsi]. [Medan]: Fakultas Kesehatan Masyarakat, Universitas Sumatera Utara; 2009.

15. Gultom E. "Karakteristik Penderita Perdarahan Antepartum Yang Dirawat Inap Di Rumah Sakit Santa Elisabeth Medan tahun 2004-2008',[Skripsi]. [Medan]: Fakultas Kesehatan Masyarakat, Universitas Sumatera Utara; 2009.

16. Y.Widyastuti dan Susilawati. "Hubungan Antara Umur dan Paritas Ibu Dengan Kejadian Plasenta Previa pada Ibu Hamil di RSUD Palembang BARI Tahun 2007''[Skripsi]. [Palembang]: Akademi Kebidanan Budi Mulia; 2007.

17. Ojemo DO, Okonofua FE. Risk factors for primary postpartum haemorrhage. Arch Gynecol Obstet 1997 Jul;259:179.

18. Kramer MS, Dahhou M, Vallerand D, Liston R, Joseph KS. Risk Factors for Postpartum Hemorrhage: Can We Explain the Recent Temporal Increase? J Obstet Gynaecol Can 2011;33(8):810-819.

19. Brown CA, Shon SB, Khan K, Lilford R, Mukhwona W. Antenatal care and perintal outcomes in Kwale district Kenya. BMC Pregnancy \& Chilbirth 2008;8; p. 1-11.

20. Ribeiro, Guimares AMDN, Betitiol $\mathbf{H}$, Lima, Almeida MLD, de Souza L, et al. Risk factor for inadequate prenatal care use in the metropolitan ares of Aracaju.Northeast Brazil. BMC Pregnancy and Chilbirth.2009;9: p.1-8. 